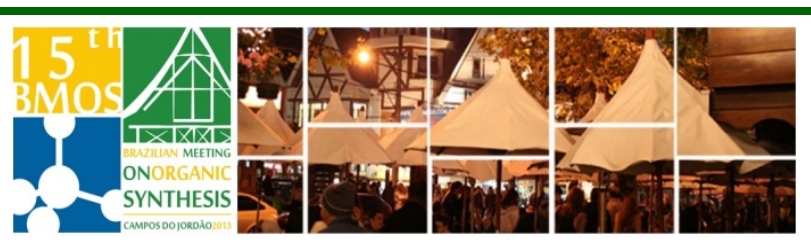

\title{
Synthesis and anti-HSV-1 activity of novel $\beta$-carbolines containing a substituted thiazolidin-4-one ring at C-3
}

\author{
Valéria Aquilino Barbosa ${ }^{1}$ (PG), Camila de Menezes Kisukuri ${ }^{1}$ (IC), Renata Sespede \\ $\operatorname{Mazia}^{2}(P G)$, Tania Ueda-Nakamura ${ }^{2}(P Q)$, Celso V. Nakamura ${ }^{2}(P Q)$ and Maria \\ Helena Sarragiotto ${ }^{*}(P Q)$ \\ ${ }^{1}$ Universidade Estadual de Maringá - Departamento de Química - Av. Colombo, 5790, Zona 07, 87020-900 \\ Maringá-PR - Brasil. ${ }^{2}$ Universidade Estadual de Maringá - Departamento de Análises Clínicas - Av. \\ Colombo, 5790, Zona 07, 87020-900 Maringá - PR - Brasil
}

\section{*mhsarragiotto@uem.br}

Keywords: $\beta$-carboline-4-thiazolidinones, synthesis, anti-HSV-1 activity.

\section{INTRODUCTION}

Compounds containing heterocyclic nucleus have shown a range of pharmacological and biological properties. Our research group has demonstrated that appropriate heterocyclic groups attached to the 3 -position of the $\beta$-carboline skeleton result in more active derivatives, with reduced toxicity ${ }^{1,2}$. In the present work, we performed the synthesis and antiviral activity evaluation of $\beta$-carboline derivatives containing a substituted 4-thiazolidinone nucleus at 3-position.

\section{RESULTS AND DISCUSSION}

The synthetic route for preparation of the $\beta$ carboline derivatives $7 a-c$ is outlined in Scheme 1 .

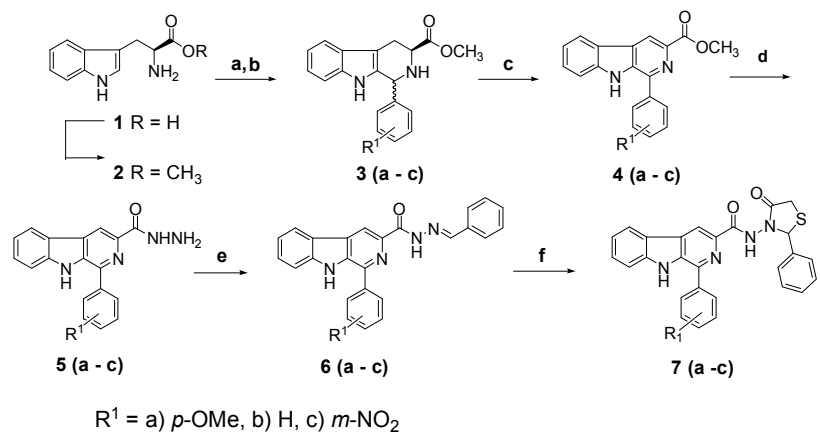

Reagents and conditions: (a) $\mathrm{MeOH}, \mathrm{H}_{2} \mathrm{SO}_{4}$ (cat), reflux, $48 \mathrm{~h}$, 92\%; (b) R ${ }^{1} \mathrm{CHO}$, TFA, DCM, rt 80-91\%; (c) $\mathrm{S}$, xylene, reflux, 48 h to $0{ }^{\circ} \mathrm{C}, 3 \mathrm{~h}, 70-90 \%$; (d) $\mathrm{NH}_{2} \mathrm{NH}_{2} \cdot \mathrm{H}_{2} \mathrm{O}$, EtOH, reflux, $48 \mathrm{~h}$, $72-91 \%$ e) $\mathrm{PhCHO}$, DMF, MW 67-83\%; f) $\mathrm{HSCH}_{2} \mathrm{COOH}, p-$ $\mathrm{TsOH}$ (cat), toluene $68-71 \%$.

Scheme 1. Synthetic route for $\beta$-carbolines 7a-c

The $\beta$-carbolines containing the 4thiazolidinone ring at 3-position (7a-c) were prepared from the commercial $L$-tryptophan (1). The Pictet Spengler condensation of the $L$ tryptophan methyl ester (2) with appropriate aromatic aldehydes, in acidic media, afforded the tetrahydro- $\beta$-carbolines $\mathbf{3 a - c}$. Oxidation of $\mathbf{3 a - c}$ with sulfur, in xylene, followed by treatment of the $\beta$-carbolines $4 a-c$ with hydrazine hydrate gave the respective carbohydrazides $\mathbf{5 a - c}$, as previously reported $^{2}$. The synthesis of the desired derivatives $7 \mathbf{a}-\mathbf{c}$ was possible by the reaction of imines $\mathbf{6 a - c}$ with mercaptoacetic acid, using catalytic $p$ toluenesulphonic acid. The intermediates 6a-c were prepared by the condensation of carbohydrazides 5a-c with benzaldehyde, in DMF, under microwave irradiation.

The antiviral activity of the synthesized compounds was performed against Herpes simplex virus type 1 (HSV-1). Derivatives 7a-c showed potent antiviral activity $\left(\mathrm{EC}_{50}\right.$ values in the range of 0.80 to $2.02 \mu \mathrm{M})$, and high selectivity (SI>200) (Table 1).

Table 1. Antiviral activity of 7a-c against HSV-1

\begin{tabular}{clll}
\hline Comp & $\mathbf{E C}_{50}{ }^{\mathbf{b}}(\boldsymbol{\mu M})$ & $\mathbf{C C}_{50}{ }^{\mathbf{a}}(\boldsymbol{\mu M})$ & $\mathbf{S I}^{\mathbf{c}}$ \\
\hline $\mathbf{7 a}$ & $0,80 \pm 0,117$ & $467 \pm 14,142$ & 592,5 \\
$\mathbf{7 b}$ & $2,15 \pm 0,424$ & $506 \pm 6,429$ & 235,0 \\
$\mathbf{7 c}$ & $2,02 \pm 0,494$ & $1080 \pm 37,859$ & 533,9 \\
\hline${ }^{\mathrm{a}}$ Concentration at which 50\% cytotoxicity is observed \\
b Concentration at which 50\% efficacy in antiviral assay is \\
observed \\
obelectivity index $\left(\mathrm{CC}_{50} / \mathrm{EC}_{50}\right)$
\end{tabular}

\section{CONCLUSION}

In this work, we have synthesized $\beta$ carboline derivatives containing a substituted 4thiazolidinone nucleus attached at position-3. The synthesized compounds showed potent antiviral activity and high selectivity against Herpes simplex virus type 1 (HSV-1).

\section{ACKNOWLEDGEMENTS}

CAPES, CNPq, Fundação Araucária, DQI-UEM

\section{REFERENCES}

${ }^{1}$ Formagio, A. S. N.; Tonin, L. T. D.; Foglio, M. A. ; Madjarof, C.; de Carvalho, J. E. ; da Costa, W. F. ; Cardoso, F. P.' Sarragiotto, M. H. ; Bioorg. Med. Chem., 2008, 16, 9660.

${ }^{2}$ Savariz, F. C.; Formagio, A. S. N.; Barbosa, V. A.; Foglio, M. A.; de Carvalho, J. E.; Duarte, M. C. T.; Filho, B. P. D.; Sarragiotto, M. H. J. Braz. Chem. Soc., 2010, 21, 288. 